Supporting information for

\title{
Orthogonal Reconstruction of Upconversion and Holographic Images for Anticounterfeiting Based on Energy Transfer
}

Mingli Ni ${ }^{1}$, Wen Luo $^{1}$, Dan Wang ${ }^{1}$, Yue Zhang ${ }^{1}$, Haiyan Peng, ${ }^{*}, 1,2$ Xingping Zhou ${ }^{*}, 1$, Xiaolin

$$
\mathrm{Xie}^{1,2}
$$

${ }^{1}$ Key Lab for Material Chemistry of Energy Conversion and Storage, Ministry of Education, and Hubei Key Lab of Materials Chemistry and Service Failure, School of Chemistry and Chemical Engineering, Huazhong University of Science and Technology, Wuhan 430074, China

${ }^{2}$ National Anti-Counterfeit Engineering Research Center, Wuhan 430074, China

Corresponding authors: hypeng@hust.edu.cn (H. Y. Peng), xpzhou@hust.edu.cn (X. P. Zhou) 
Table S1. Formulations for fabricating holographic polymer nanocomposites

\begin{tabular}{cccccc}
\hline Entry & $\begin{array}{c}\text { DMAA+6361-100a } \\
(\mathrm{wt} \%)\end{array}$ & $\begin{array}{c}\text { P0616A } \\
(\mathrm{wt} \%)\end{array}$ & $\begin{array}{c}\mathrm{UCNP} \\
(\mathrm{wt} \%)\end{array}$ & $\begin{array}{c}\mathrm{KCD}^{\mathrm{b}} \\
(\mathrm{wt} \%)\end{array}$ & $\begin{array}{c}\mathrm{NPG}^{\mathrm{b}} \\
(\mathrm{wt} \%)\end{array}$ \\
\hline I & 70 & & 0 & & \\
II & 65 & 30 & 10 & 0.6 & 1.3 \\
III & 60 & & 15 & & \\
IV & 55 & & 20 & & \\
V & 50 & & & & \\
\hline
\end{tabular}

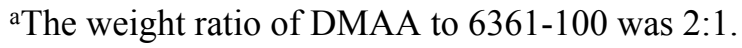

${ }^{\mathrm{b}}$ The weight ratio to the total mass of DMAA, 6361-100, P0616A and UCNP.

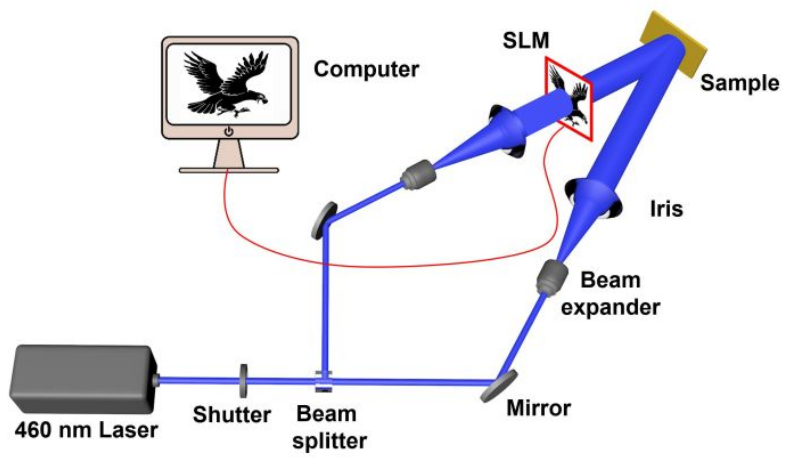

Figure S1. Schematic illustration of the optical settings for reconstructing holographic images.

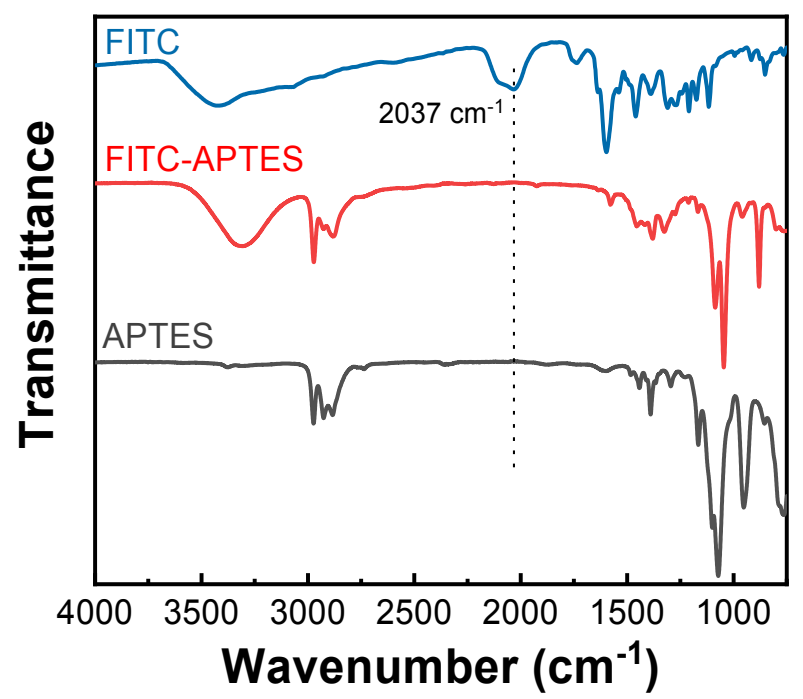

Figure S2. FTIR spectra of FITC, APTES and mixture of FITC and APTES (weight ratio = 1:5) after reacting under room temperature for $12 \mathrm{~h}$. The disappearance of the peak at $2037 \mathrm{~cm}^{-1}$ corresponding to the stretching vibration of $\mathrm{N}=\mathrm{C}=\mathrm{S}$ indicates a full conversion of FITC. 


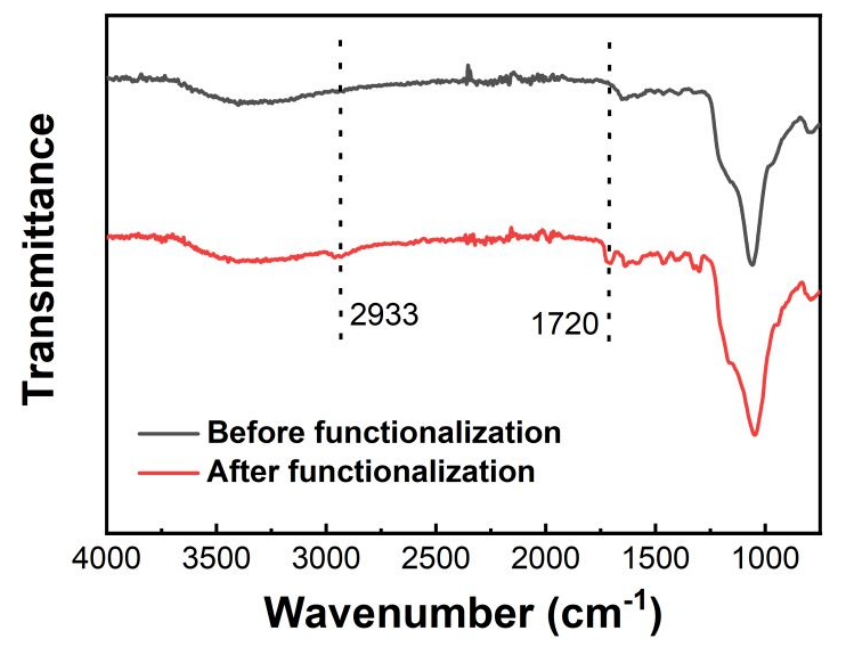

Figure S3. FTIR spectra of UCNP before and after functionalization with MPS. The emerging peaks at 2933 and $1720 \mathrm{~cm}^{-1}$ correspond to the stretching vibration of $\mathrm{C}-\mathrm{H}$ and $\mathrm{C}=\mathrm{O}$ of MPS, respectively.

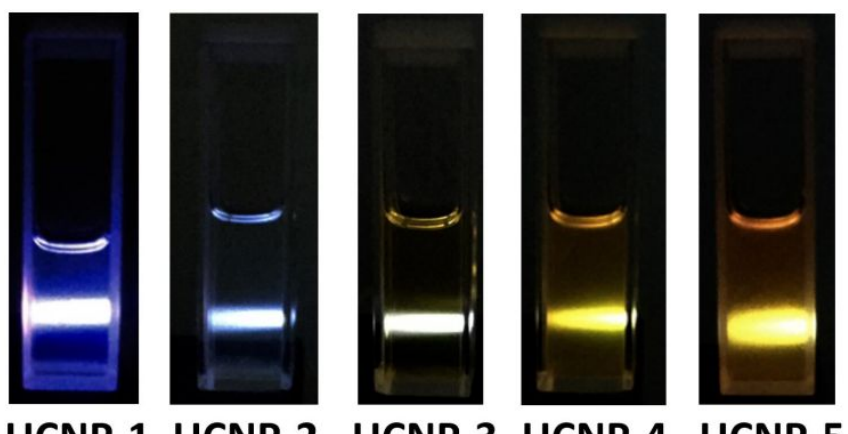

UCNP-1 UCNP-2 UCNP-3 UCNP-4 UCNP-5

Figure S4. Emission of UCNP when dispersed in DMAA. Concentration: $30 \mathrm{mg} / \mathrm{mL}$; excitation wavelength: $980 \mathrm{~nm}$.

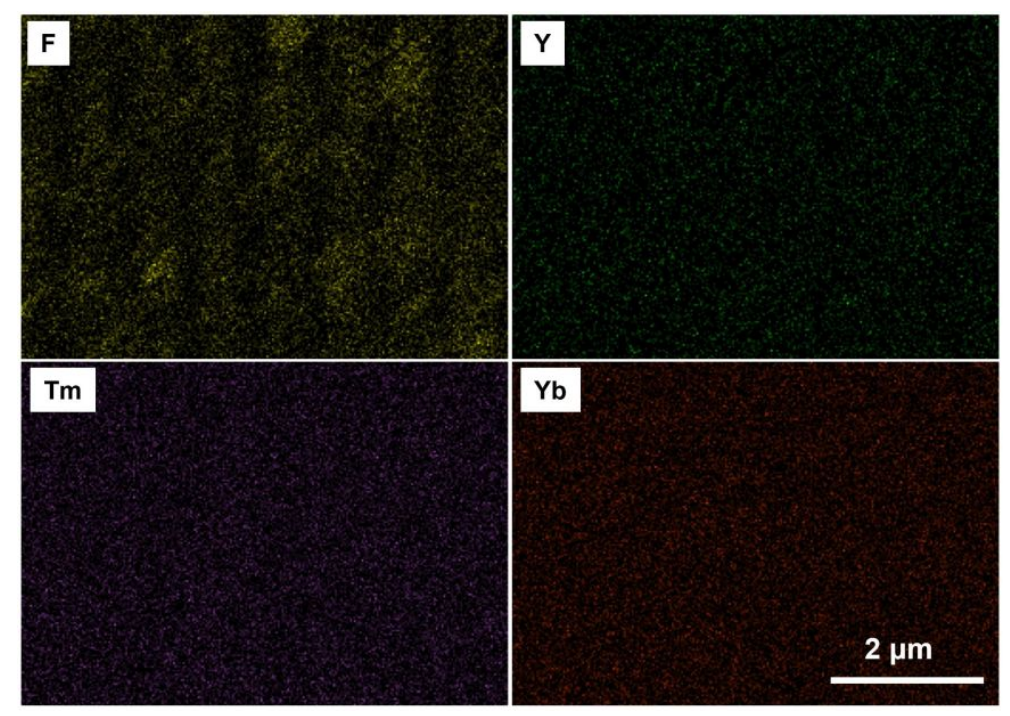

Figure S5. Elemental (F, Y, Tm and $\mathrm{Yb}$ ) mapping of holographic polymer nanocomposites containing $15 \mathrm{wt} \%$ of the UCNP. The LC was removed prior to characterization. 


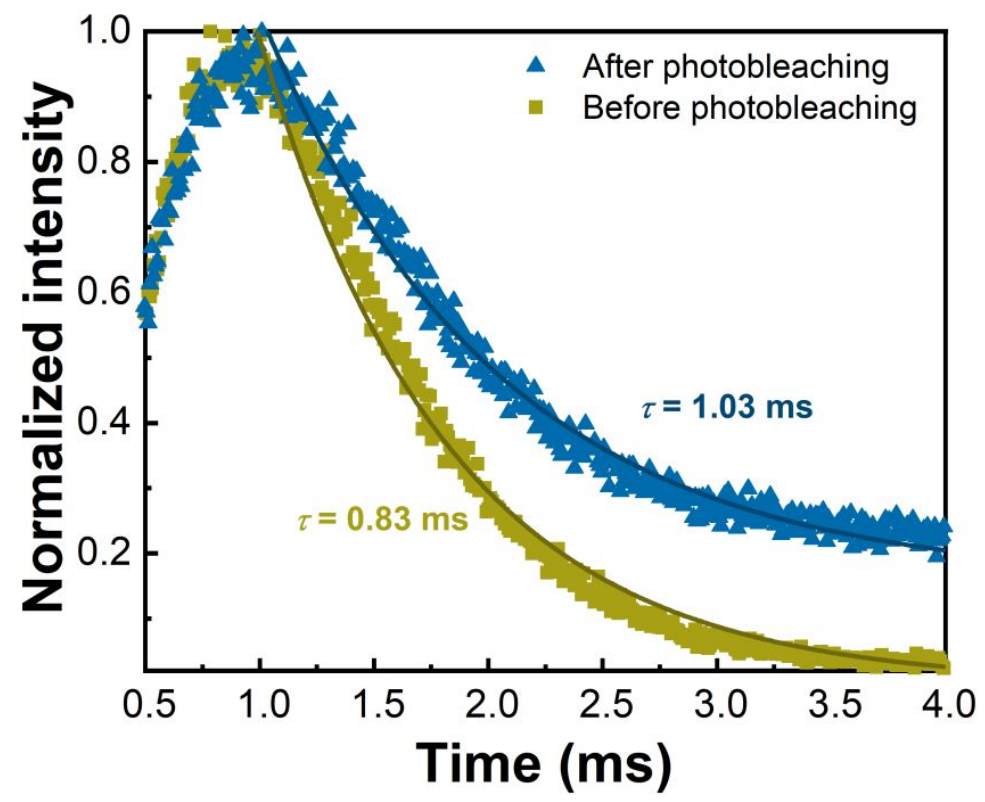

Figure S6. Upconversion emission decay of UCNP-4 that is monitored at $475 \mathrm{~nm}$ before and after photobleaching. The upconversion emission lifetime is given by fitting the decay curves using a pseudo-first-order exponential function.

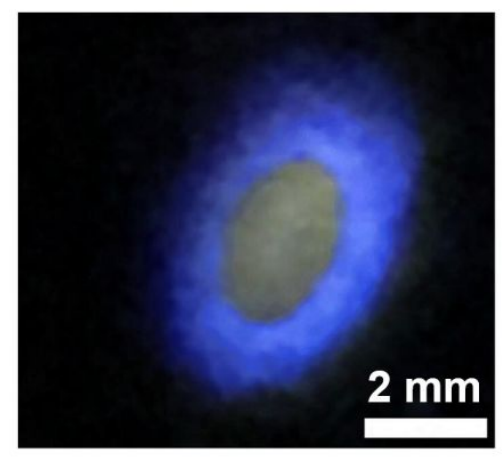

Figure S7. Reconstructed upconversion image in the holographic polymer nanocomposites which looks like a "nebula". 